\title{
Online Gaming, Internet Addiction, and Aggression in Chinese Male Students: The Mediating Role of Low Self-Control
}

\author{
Zhaojun Teng ${ }^{1}$, Yujie $\mathrm{Li}^{1} \&$ Yanling Liu ${ }^{1,2}$ \\ ${ }^{1}$ Research Center of Mental Health Education \& Faculty of Psychology, Southwest University, Chongqing, China \\ ${ }^{2}$ Key Laboratory for NeuroInformation of Ministry of Education \& School of Life Science and Tecnology, \\ University of Electronic Science and Technology of China, Chengdu, China \\ Correspondence: Yanling Liu, Faculty of Psychology, Southwest University, No.2, Tiansheng Street, Beibei \\ District, Chongqing, China. Tel: 86-862-354-8686. E-mail: ssq@swu.edu.cn
}

\author{
Received: February 16, $2014 \quad$ Accepted: May 3, $2014 \quad$ Online Published: May 19, 2014 \\ doi:10.5539/ijps.v6n2p89 \\ URL: http://dx.doi.org/10.5539/ijps.v6n2p89
}

\begin{abstract}
Even though the General Aggression Model suggests that personality and situational variables can influence aggression, it is not clear if the model can be applied to Eastern cultures. The present study examined the mediating role of low self-control in the relationships between violent online gaming, Internet addiction, and aggression. We conducted a cross-sectional study using online self-report questionnaires to assess violent online game exposure, Internet addiction, low self-control, and aggression in 211 Chinese male students. We found that the majority of the 10 most popular games reported by the participants were violent. There were positive correlations between violent online game exposure, Internet addiction, low self-control, and aggression. Aggression was not only directly predicted by violent online game exposure and Internet addiction, but also mediated by low self-control. These findings support the development of educational programs and measures to cultivate self-control in college students and reduce aggression engendered by playing violent online games. Aggression and self-control, which is conducive to educational interventions, are related. The implications and limitations of this study are discussed.
\end{abstract}

Keywords: violent online game exposure, Internet addiction, low self-control, aggression

\section{Introduction}

With the growth of the Internet, more people have access to online games. Online gaming is a popular form of entertainment that influences the quality of life of players (Shen \& Williams, 2011). A specific type of gaming that involves violent online game exposure (VOGE) is of considerable concern to researchers, regulators, and the public.

A particular concern is that playing online violent games can influence aggression in both the short and long term (Anderson \& Bushman, 2002) by influencing cognitive and emotional beliefs (Anderson et al., 2010). According to the General Aggression Model, people exposed to highly violent video games are more likely to exhibit aggressive cognitions and beliefs (Anderson \& Bushman, 2002). Aggression is defined as any behavior directed toward another individual carried out with the proximate intent to cause harm (Anderson \& Bushman, 2002). Aggression is affected by personality variables (e.g., self-control) and situational variables (e.g., media exposure to violence). People with personality traits such as neuroticism, depression, and low self-control are believed to be more susceptible to developing aggressive behavior (Jones, Miller, \& Lynam, 2009; Teng \& Liu, 2013; Verona, Patrick, \& Lang, 2002).

Another concern is that long periods of online game playing may lead to online game addiction (or Internet Gaming Disorder, according to the DSM- IV). Online game addiction has a negative correlation with self-control and a positive correlation with aggression (Kim, Namkoong, Ku, \& Kim, 2008).

Self-control is a personality variable often negatively linked to online game addiction and VOGE, presumably because it results in playing online violent games for long periods, which, in turn, could have a further detrimental effect on self-control (Frostling-Henningsson, 2009; Kim et al., 2008). Low self-control (i.e., not monitoring behaviors and impulses) may result in aggressive actions, anger, and general aggressive tendencies (Mehroof \& Griffiths, 2010); such aggressive and violent behaviors can be restrained by self-control (Chen, Liu, 
Lei, \& Cui, 2012; Denson, Capper, Oaten, Friese, \& Schofield, 2011; DeWall, Deckman, Gailliot, \& Bushman, 2011). Increasing self-control could reduce aggression (Hamama \& Ronen-Shenhav, 2012). Moreover, low self-control as a mediator between situational variables and aggression is supported by a wealth of research (DeWall et al., 2011; Li, Li, \& Newman, 2013; Runions, 2013; Winstok, 2009). Low self-control could also play a mediating role in predicting aggression and violence (DeWall et al., 2011; Ozdemir, Vazsonyi, \& Cok, 2013; Qu \& Zou, 2009) as it has been shown to play a mediating role in situational variables (e.g., parenting processes) that predict aggression (Ozdemir et al., 2013). Other studies have demonstrated the mediating effect of parental behavior on aggression (Kim et al., 2008; Ronen, Abuelaish, Rosenbaum, Agbaria, \& Hamama, 2012).

The findings cited above support self-control theory (Gottfredson \& Hirschi, 1990; Grasmick, Tittle, Bursik, \& Arneklev, 1993); low self-control may be a key predictor of deviant behaviors and is hypothesized to be the main cause of long-term online gaming or Internet addiction. Students with Internet addiction are generally less able to alter their environments because of the side effects of addiction ( $\mathrm{Ng} \&$ Wiemer-Hastings, 2005), and a lack of self-control prevents them from monitoring their online behaviors (Gottfredson \& Hirschi, 1990). Violent online gaming has been associated with an increased risk of Internet addiction disorder and aggression (Grusser, Thalemann, \& Griffiths, 2007; Kim et al., 2008; Ng, \& Wiemer-Hastings, 2005). Previous studies found that aggression was positively correlated with low self-control (Grusser et al., 2007; Mehroof \& Griffiths, 2010; Kim et al., 2008; Ko, Yen, Liu, Huang, \& Yen, 2009). Montag et al. (2011) found bidirectional predictive variables aligned with low self-directedness and Internet addiction. Their data suggest a continuum model, in which low self-directedness is highly correlated with Internet addiction for first-person-shooter video gamers and college students.

The interrelationships between Internet use, self-control, and aggression can be explained in light of the work of Young (1998), who postulated that Internet addiction is an impulse control disorder (as defined by DSM-IV criteria). Specifically, using the Internet for long periods and spending an excessive amount of time playing online games could lead to impaired self-control characteristics, such as those in impulse control disorders. Impulsive individuals have difficulty constraining their attempts to satisfy their desires, and, as a result, they are more likely to become aggressive. In summary, the literature suggests that online violent gaming may increase the risk of aggression by increasing angry feelings and hostile thoughts through the combination of situational and personality variables (Anderson \& Bushman, 2002).

Despite extensive research on the psychological effects of online gaming in Western cultures, little research has been carried out with Chinese participants, even though a recent Chinese video game marketing report showed that $95 \%$ of online games in China contain violent, aggressive, and provocative content (Yan, 2013). A preliminary study in China suggested that online game dependency predicted various problems, such as physical, personal life, and academic problems. These problems were usually associated with poor human performance (Peng \& Liu, 2010). Few studies have addressed Internet addiction and online gaming in Asian individuals; indeed, most evidence has been obtained from research in Western cultures. Thus, whether the findings of such studies generalize to China is unknown. To fill this gap, the present study investigated the relationship between VOGE, online addiction, low self-control, and aggression among Chinese male students.

\section{Method}

\subsection{Participants}

According to a study by Ng and Wiemer-Hastings (2005), male college students frequently participate in online games; therefore, this group was selected as the target population. Using a random group sampling method, a questionnaire was sent to 250 male college students $(M=21.62$ years, $S D=2.19$; range: $18-27$ years $)$ from seven Chinese colleges in Chongqing, Chengdu, and Beijing. Two hundred and eleven valid questionnaires were returned (response rate: $84.40 \%$ ). The sample included 84 urban residents and 127 rural residents, and 78 respondents were the only children in their families.

\subsection{Materials}

\subsubsection{Violent Online Game Exposure}

The instrument we used to measure violent online game exposure was designed by Anderson and Dill (2000). First, participants were asked to list their five favorite online games. After naming each game, participants were asked to use a seven-point Likert scale to rate often they played the game $(1=$ rarely to $7=$ often $)$, the violence of the game content $(1=$ little or no violence to $7=$ extremely violent $)$, and the violence of the game graphics $(1$ $=$ no violent graphics to $7=$ extremely violent graphics). The frequency scale included occasionally as the midpoint response (i.e., 4). The average rating of the five online games listed by each participant was considered 
the overall index of exposure to online game violence (Anderson \& Dill, 2000). For each participant, we computed a violence exposure score for each of their five favorite games by summing the violent content and violent graphics ratings and then multiplying this by playing frequency. Cronbach's $\alpha$ was .78 in this study.

\subsubsection{Internet Addiction}

This was measured using a revision of the eight-item scale developed by Young (1998). The Chinese version contains 10 items based on the clinical experience of medical workers in China (Wang, Zhao, \& Zhao, 2006). Responses choices are dichotomous $(1=$ yes, $0=$ no), with the total score ranging from 0 to 10 points; higher scores indicated higher levels of Internet addiction. An example item is "I want to surf the Internet even when I am offline". This scale has high internal consistency reliability (Cronbach's $\alpha=.74$ ) and it has been used in previous research (Wang et al., 2006).

\subsubsection{Low Self-Control}

To measure the self-control of the participants, we used the scale of low self-control designed by Grasmick et al. (1993). The Chinese version of this scale was revised by Qu and Zou (2009). It contains 16 items divided into three subscales: impulsivity and risky behavior, simple tasks, and oversimplification. The items are rated on a five-point Likert scale $(1=$ strongly disagree to $5=$ strongly agree $)$. A sample item is "I often act on the spur of the moment without stopping to think." Higher scores indicate lower levels of self-control. Consistent with previous studies (Qu \& Zou, 2009; Wang et al., 2006), the reliability estimate for this scale was high (Cronbach's $\alpha=.71$ ). Confirmatory factor analysis (CFA) has revealed good fit indices for a three-factor model $\left(\chi^{2} / d f=2.24, \mathrm{NFI}=.904, \mathrm{TLI}=.892, \mathrm{CFI}=.924, \mathrm{RMSEA}=.042, \mathrm{SMRM}=.053\right)$.

\subsubsection{Buss and Perry Aggression Questionnaire}

Participants completed the Buss and Perry Aggression Questionnaire (AQ; Buss \& Perry, 1992), a self-report measure of aggression. The AQ is a 29-item instrument designed to measure four dimensions of aggression: anger, hostility, verbal aggression, and physical aggression. Responses are made on a five-point Likert scale $(1=$ strongly disagree to $5=$ strongly agree). An example item is "If a person hits me, I hit them back." This version has been reported to have adequate reliability and validity in Chinese samples (Liu, Zhu, \& Gu, 2009). The internal consistency of this scale was high in this study (Cronbach's $\alpha=.84$ ). CFA found good fit indices for a four-factor model $\left(\chi^{2} / d f=2.05, \mathrm{NFI}=.915, \mathrm{TLI}=.906, \mathrm{CFI}=.932, \mathrm{RMSEA}=.054, \mathrm{SMRM}=.052\right)$.

\subsection{Procedure}

We sent e-mails with a link to the online survey between December 2012 and January 2013 to approximately 250 male students, requesting their participation. Participants were instructed to read the background and aims of the study before completing the online gaming questionnaire and the online addiction scales. The survey took approximately 15 minutes to complete. Once the survey was completed, the participants sent the data to an automatic SPSS 16.0 coding system. Surveys with missing data were excluded. We used AMOS 7.0 to compute the model of the data.

\subsection{Statistical Analyses}

The data was analyzed by SPSS 16.0 and AMOS 7.0 software. We counted the top 10 most popular online video games, and computed the frequency, violent content, and violent scenes of those games. Second, we analyzed the Pearson correlations between VOGE (average rating of the top five video games; Anderson \& Dill, 2000), Internet addiction, low self-control, and aggression. Structural equation modeling was use to analyze the mediating effect of low self-control in the relationships between VOGE, Internet addiction, and aggression, and several indices were used to evaluate the model fit (Hu \& Bentler, 1999; Quintana \& Maxwell, 1999). The indirect effect of low self-control on VOGE as a predictor of aggression was calculated with a bootstrapping estimation procedure (1000 reiterations). We used bootstrap estimation because we did not know the distribution of the mediator effects, even though the predictor variables and independent variables followed a Gaussian distribution.

\section{Results}

\subsection{The Top 10 Most Popular Online Video Games}

The top 10 most popular online video games are listed in Table 1. The three most popular online video games (Counter-Strike, World of Warcraft, and Crossfire) were ranked higher than 4 for violent context and imagery. Thus, our results suggested that violent online games are very popular among Chinese male students. 
Table 1. Online games of male students playing (Ranking 10)

\begin{tabular}{llllll}
\hline Name of games & Ranking & Proportion & $\begin{array}{l}\text { Frequency } \\
\mathrm{M}(\mathrm{SD})\end{array}$ & $\begin{array}{l}\text { Violent content } \\
\mathrm{M}(\mathrm{SD})\end{array}$ & $\begin{array}{c}\text { Violent scenes } \\
\mathrm{M}(\mathrm{SD})\end{array}$ \\
\hline $\begin{array}{l}\text { Counter-Strike } \\
\text { World of Warcraft }\end{array}$ & 2 & $38.09 \%$ & $4.57(0.23)$ & $4.67(0.38)$ & $5.03(0.15)$ \\
$\begin{array}{l}\text { Crossfire } \\
\text { Chinese poker }\end{array}$ & 3 & $32.38 \%$ & $5.07(0.10)$ & $4.91(0.46)$ & $5.08(0.46)$ \\
$\begin{array}{l}\text { Defence of the } \\
\text { ancient }\end{array}$ & 5 & $29.52 \%$ & $4.45(0.18)$ & $4.21(0.09)$ & $5.12(0.31)$ \\
$\begin{array}{l}\text { Call of duty } \\
\text { Plants vs. Zombies }\end{array}$ & 7 & $25.71 \%$ & $3.36(0.45)$ & $1.02(0.02)$ & $1.21(0.28)$ \\
$\begin{array}{l}\text { Pro Evolution } \\
\text { Soccer }\end{array}$ & 8 & $19.04 \%$ & $3.62(0.55)$ & $4.94(0.42)$ & $5.13(0.26)$ \\
$\begin{array}{l}\text { Legends of the } \\
\text { three kingdoms }\end{array}$ & 9 & $14.28 \%$ & $3.32(0.34)$ & $3.12(0.02)$ & $5.25(0.29)$ \\
QQ spend & 10 & $12.38 \%$ & $4.21(0.24)$ & $2.77(0.28)$ & $2.29(0.24)$ \\
\hline
\end{tabular}

\subsection{The Relationships between VOGE, Internet Addiction, Low Self-Control, and Aggression}

As reported in Table 2, VOGE $(M=20.14, S D=12.37)$ was significantly and positively correlated with Internet addiction $(M=2.38, S D=2.12)$, low self-control $(M=2.58, S D=0.43)$, and aggression $(M=2.76, S D=0.47)$.

Table 2. The relations between VOGE, Internet addiction, low self-control and aggression $(\mathrm{N}=211)$

\begin{tabular}{lllll}
\hline & 1 & 2 & 3 & 4 \\
\hline 1.Violent online game exposure & 1.00 & & & \\
2.Internet addiction & $0.24^{* *}$ & 1.00 & & \\
3.Low self-control & $0.17^{*}$ & $0.35^{* *}$ & 1.00 & \\
4.Aggression & $0.27^{* *}$ & $0.29^{* *}$ & $0.61^{* *}$ & 1.00 \\
$M(S D)$ & $20.14(12.37)$ & $2.38(2.12)$ & $2.58(0.43)$ & $2.76(0.47)$ \\
$\operatorname{Max}($ Min) & $63.20(2.00)$ & $9.00(0.00)$ & $3.75(1.33)$ & $4.26(1.52)$ \\
\hline
\end{tabular}

Note: ${ }^{*} p<0.05,{ }^{* *} p<0.01$

\subsection{The Model of VOGE, Internet Addiction, Low Self-Control, and Aggression}

The mediating effect of low self-control was analyzed by the Bentler and Bonnet method (1980). The fit indices of three models (Figure 1) are in Table 3. The fit indices for Model $\mathrm{C}$ are superior to those for the full-factor model (Model A, $\left.\chi^{2}(8, n=211)=90.25, p<.01\right)$ and the full-mediating-role model (Model B, $\chi^{2}(26, n=211)=$ $73.56, p<.01)$. For Model A, VOGE and Internet addiction explained $39 \%$ of the variance in aggression, and VOGE $(\beta=.24, p<.01)$ and Internet addiction $(\beta=.30, p<.01)$ positively predicted aggression. In Model $\mathrm{B}$, VOGE and Internet addiction explained $14 \%$ of the variance in low self-control, and VOGE $(\beta=.14, p<.05)$ and Internet addiction $(\beta=.33, p<.01)$ positively predicted aggression. Low self-control explained $38 \%$ of the variance in aggression $(\beta=.59, p<.01)$ and positively predicted aggression. There was no significant difference between Models A and B $\left(\Delta \chi^{2}=22.69, \Delta d f=18, p>.05\right)$; however, there was a dramatic difference between Models B and C $\left(\Delta \chi^{2}=21.82, \Delta d f=3, p<.01\right)$.

Regarding the mediating role of low self-control in the VOGE and Internet addiction prediction of aggression, the Model C appeared to fit the data well. VOGE and Internet addiction explained $12 \%$ of the variance in low self-control. VOGE positively predicted low self-control $(\beta=.17, p<0.05)$ and aggression $(\beta=.16, p<.05)$. VOGE, Internet addiction, and low self-control explained $34 \%$ of the variance in aggression. Internet addiction 
positively predicted low self-control $(\beta=.35, p<.01)$, and low self-control predicted aggression $(\beta=.64, p$ $<.01$ ). Based on these predictive values, we used bootstrapping (bootstrapping samples $=1000$ ) to analyze the mediating effect of low self-control. Results showed that VOGE and Internet addiction indirectly predicted aggression through the mediator of low self-control $(.078, S E=.035,95 \% C I[.011, .156], p<.05 ; .148, S E$ $=.041,95 \%$ CI $[.077, .241], p<.01$, respectively). Thus, our model indicated that VOGE predicted aggression (explaining $31.2 \%$ of the variance in aggression via the mediating role of low self-control) and, when Internet addiction was added, the explained variance was increased to $59.2 \%$.
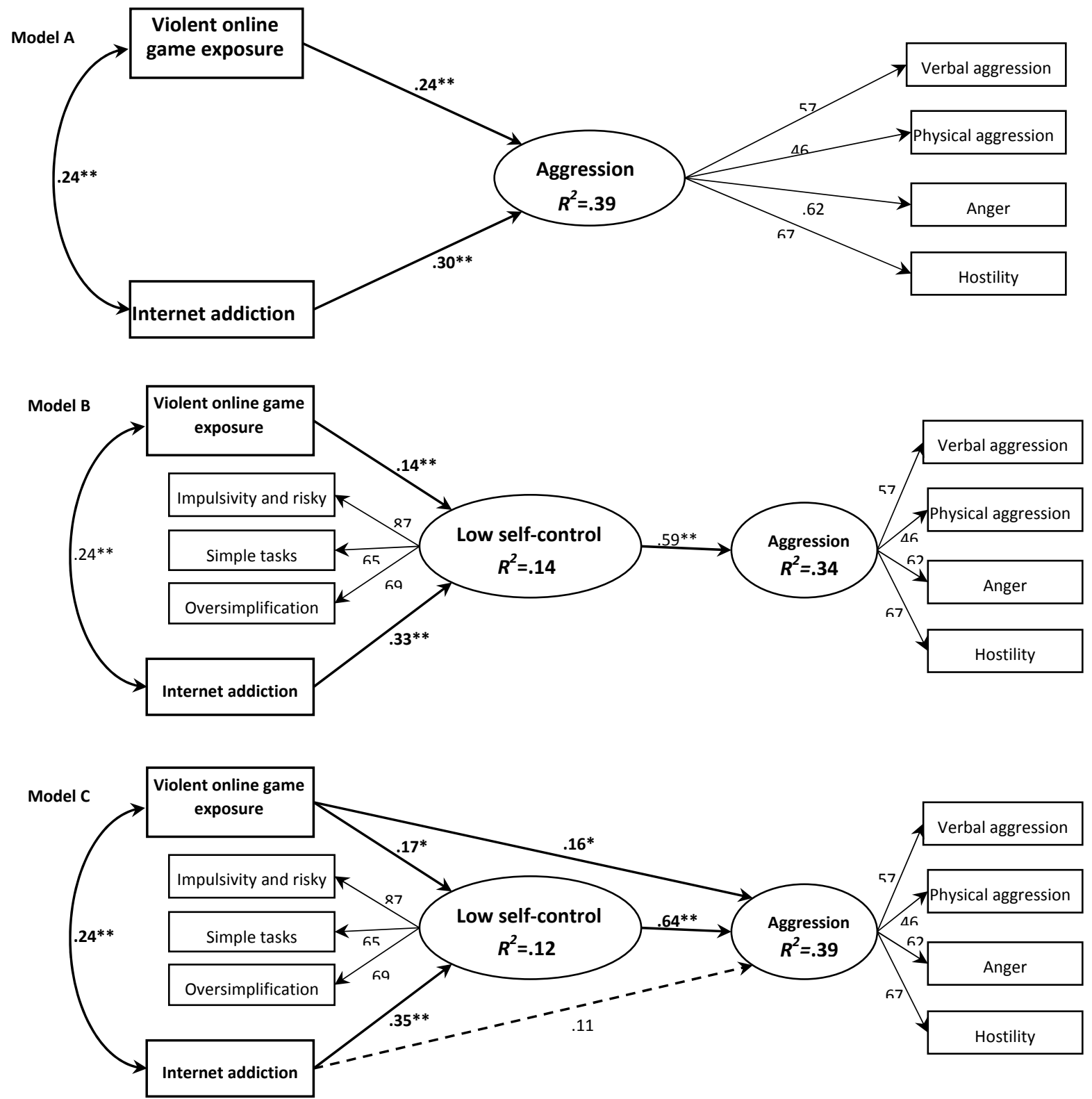

Figure 1. The models of violent online game exposure, Internet addiction, low self-control, and aggression

Note. Solid lines indicate significant effects $\left({ }^{*} p<.05,{ }^{* *} p<.01\right)$, while the dashed line indicates a non-significant effects $(p>.05)$. 
Table 3. The model fit of VOGE, internet addiction, low self-control, and aggression $(\mathrm{N}=211)$

\begin{tabular}{lllllllllll}
\hline & $\chi^{2}$ & $d f$ & $\chi^{2} / d f$ & NFI & TLI & CFI & RMSEA & SMRM & $\Delta \chi^{2}$ & $\Delta d f$ \\
\hline Model A & 96.25 & 8 & 12.03 & .756 & .764 & .792 & .152 & .143 & & \\
Model B & 73.56 & 26 & 2.83 & .829 & .833 & .880 & .093 & .078 & 22.69 & 18 \\
Model C & 51.74 & 23 & 2.25 & .913 & .895 & .914 & .077 & .063 & 21.82 & 3 \\
\hline
\end{tabular}

Note. NFI, normed fit index; TLI, Tucker-Lewis index; CFI, comparative fit index; RMSEA, root mean square error of approximation; SRMR, standardized root mean square residual. According to Wen, Hau, and Marsh's Cutoff criteria for goodness of fit, RMSEA should be less than 0.08 (Wen, Hau, \& Marsh, 2004).

\section{Discussion}

The present study identified the top 10 most popular online games among 211 male students in China; Counter-Strike (Note 1), World of Warcraft (Note 2), and Crossfire (Note 3) were the most popular. These online games were rated as violent, aggressive, and competitive. Previous research has already examined these characteristics (e.g. violence), for example, Counter-Strike has been assessed in the literature (Frostling-Henningsson, 2009; Lemmens \& Bushman, 2006). These studies found that violent online games may contribute to the addictive nature of online gaming.

The present study also examined the role of low self-control in the relationship between situational variables (VOGE and online addiction) and aggression. We found significant relationships between online addiction, aggression, VOGE, and low self-control. Consistent with the literature, high VOGE was associated with high aggression and low self-control (Kim et al., 2008; Ozdemir et al., 2013). According to the General Aggression Model, exposure to media violence might increase aggression by modulating emotional and cognitive beliefs.

We also found that online addiction was positively correlated with aggression and low self-control, which is consistent with previous research (Kim et al., 2008; Ko et al., 2009). Male college students spend a long time playing online games, and often they get together in a group to do so, which might engender group polarization(Kim et al., 2008). In other words, individuals who respond powerfully might have an even greater response when supported by the group than those who are not in a group or do not have problems related to excessive online gaming (Kim et al., 2008). This may be one mechanism in the association of online addiction and gaming with low self-control and high aggressive behaviors.

Our results, however, should be interpreted with caution. Mehroof and Griffiths (2010) found no evidence that online game addiction was associated with self-control. However, this may have been due to the relatively small sample size (123 participants) in their study. The present finding that low self-control significantly predicts aggression concurs with the results of other studies (DeWall et al., 2011; Hamama \& Ronen-Shenhav, 2012; Kim et al., 2008; Ozdemir et al., 2013).

Moreover, we also found that low self-control, VOGE, and Internet addiction are all associated with aggression. Specifically, low self-control plays a mediating role in the relationship between VOGE and aggression, and directly predicts addiction. The General Aggression Model may explain this result (Anderson \& Bushman, 2002). Self-control is a personality variable that not only contributes to modulating aggression but also to the development of positive psychological characteristics, which, in versa, might exert a negative influence on Internet addiction. On the other hand, extensive online gaming is positively linked to Internet addiction, which might engender low self-control. According to General Aggression Model, low self-control might be interacting with other situational variables, such as online behaviors, to produce aggressive behavior and violence (Anderson \& Bushman, 2002). Hence, the General Aggression Model could explain the mediating effect of low self-control in the prediction of aggression in Chinese male students.

Although this study makes a significant contribution by examining the relationship between VOGE, online addiction, low self-control, and aggression in Chinese participants, there are some limitations. First, we employed a cross-sectional design; therefore, causal relationships between VOGE, online addiction, low self-control, and aggression cannot be determined. In the future, longitudinal studies should be conducted to address causality. Another limitation is the selection of only male participants; therefore, our results cannot be generalized to females. Finally, although self-control was found to be an important predictor of aggression, it is unlikely to be the sole trigger of aggressive behaviors. Further studies should focus on the integration of self-control theory and other theories, such as GAM theory, to better understand addiction to violent online gaming and the resulting aggression. 
Nevertheless, the results of the research support the development of interventions for college students aimed at increasing protective factors, such as self-control, to reduce aggression engendered by playing violent online games and online gaming addictions. A better understanding of VOGE, online addiction, and low self-control will permit counselors and educators to intervene to reduce aggression in real-world contexts. The present findings show that low self-control is an important risk factor for aggression, and thus, self-control should be cultivated in a range of settings, including colleges.

\section{Conclusion}

The aim of the study was to investigate the relationship between VOGE and online addiction, low self-control, and aggression among Chinese male students. The results revealed that the three most popular online video games (Counter-Strike, World of Warcraft, and Crossfire) were ranked higher than average for violent context and imagery. We also found that there were positive correlations between VOGE, Internet addiction, low self-control, and aggression. Aggression was not only directly predicted by VOGE and Internet addiction but also mediated by low self-control. These findings support the development of educational programs to increase self-control in college students, which may help alleviate aggression engendered by playing violent online games.

\section{Acknowledgements}

This study was supported by the Fundamental Research Funds for the Central Universities of "Online Game Playing Impact on College Students' Aggression and Its Neural Mechanism" (SWU1409118) and the Construction Research Team fund of the project "Effect of Network Media on the Aggression of Youth and Its Neural Mechanism" of the Faculty of Psychology of Southwest University of China (TR201204-5).

\section{References}

Anderson, C. A., \& Bushman, B. J. (2001). Effects of violent video games on aggressive behavior, aggressive cognition, aggressive affect, physiological arousal, and prosocial behavior: A meta-analytic review of the scientific literature. Psychological Science, 12(5), 353-359. http://dx.doi.org/10.1111/1467-9280.00366

Anderson, C. A., \& Bushman, B. J. (2002). Human aggression. Annual Review of Psychology, 53(1), 27-51. http://dx.doi.org/10.1146/annurev.psych.53.100901.135231

Anderson, C. A., \& Dill, K. E. (2000). Video games and aggressive thoughts, feelings, and behavior in the laboratory and in life. Journal of Personality and Social Psychology, 78(4), 772-790. http://dx.doi.org/10.1037/0022-3514.78.4.772

Anderson, C. A., Shibuya, A., Ihori, N., Swing, E. L., Bushman, B. J., Sakamoto, A., ... \& Saleem, M. (2010). Violent video game effects on aggression, empathy, and prosocial behavior in eastern and western countries: a meta-analytic review. Psychological Bulletin, 136(2), 151-173. http://dx.doi.org/10.1037/a0018251

Bentler, P. M., \& Bonett, D. G. (1980). Significance tests and goodness of fit in the analysis of covariance structures. Psychological bulletin, 88(3), 588-606. http://dx.doi.org/10.1037/0033-2909.88.3.588

Buss, A. H., \& Perry, M. (1992). The aggression questionnaire. Journal of Personality and Social Psychology, 63(3), 452-459. http://dx.doi.org/10.1037/0022-3514.63.3.452

Chen, R., Liu, Y., Lei, H., \& Cui, W. (2012). The relationship of self-control and aggressive behavior in College students. Chinese Journal of Behavioral Medicine and Brain Science, 21(8), 751-753. http://dx.doi.org/10.3760/cma.j.issn.1674-6554.2012.08.025

Denson, T. F., Capper, M. M., Oaten, M., Friese, M., \& Schofield, T. P. (2011). Self-control training decreases aggression in response to provocation in aggressive individuals. Journal of Research in Personality, 45(2), 252-256. http://dx.doi.org/10.1016/j.jrp.2011.02.001

DeWall, C. N., Deckman, T., Gailliot, M. T., \& Bushman, B. J. (2011). Sweetened blood cools hot tempers: Physiological self-control and aggression. Aggressive Behavior, 37(1), 73-80. http://dx.doi.org/10.1002/ab.20366

Frostling-Henningsson, M. (2009). First-Person Shooter Games as a Way of Connecting to People: "Brothers in Blood". Cyberpsychology \& Behavior, 12(5), 557-562. http://dx.doi.org/10.1089/cpb.2008.0345

Grasmick, H. G., Tittle, C. R., Bursik, R. J., \& Arneklev, B. J. (1993). Testing the Core Empirical Implications of Gottfredson and Hirschi General-Theory of Crime. Journal of Research in Crime and Delinquency, 30(1), 5-29. http://dx.doi.org/10.1177/0022427893030001002 
Grusser, S. M., Thalemann, R., \& Griffiths, M. D. (2007). Excessive computer game playing: Evidence for addiction and aggression? Cyberpsychology \& Behavior, 10(2), 290-292. http://dx.doi.org/10.1089/cpb.2006.9956

Hamama, L., \& Ronen-Shenhav, A. (2012). Self-control, social support, and aggression among adolescents in divorced and two-parent families. Children and Youth Services Review, 34(5), 1042-1049. http://dx.doi.org/10.1016/j.childyouth.2012.02.009

Hu, L. T., \& Bentler, P. M. (1999). Cutoff criteria for fit indexes in covariance structure analysis: Conventional criteria versus new alternatives. Structural Equation Modeling: A Multidisciplinary Journal, 6(1), 1-55. http://dx.doi.org/10.1080/10705519909540118

Jones, S. E., Miller, J. D., \& Lynam, D. R. (2011). Personality, antisocial behavior, and aggression: A

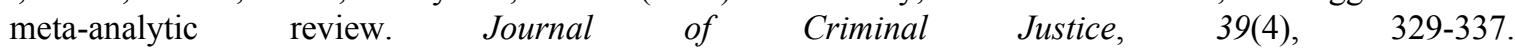
http://dx.doi.org/10.1016/j.jcrimjus.2011.03.004

Kim, E. J., Namkoong, K., Ku, T., \& Kim, S. J. (2008). The relationship between online game addiction and aggression, self-control and narcissistic personality traits. European Psychiatry, 23(3), 212-218. http://dx.doi.org/10.1016/j.eurpsy.2007.10.010

Ko, C. H., Yen, J. Y., Liu, S. C., Huang, C. F., \& Yen, C. F. (2009). The associations between aggressive behaviors and internet addiction and online activities in adolescents. Journal of Adolescent Health, 44(6), 598-605. http://dx.doi.org/10.1016/j.jadohealth.2008.11.011

Lemmens, J. S., \& Bushman, B. J. (2006). The appeal of violent video games to lower educated aggressive adolescent boys from two countries. Cyberpsychology \& Behavior, 9(5), 638-641. http://dx.doi.org/10.1089/cpb.2006.9.638

Li, X., Li, D., \& Newman, J. (2013). Parental behavioral and psychological control and problematic Internet use among Chinese adolescents: The mediating role of self-control. Cyberpsychology, Behavior, and Social Networking, 16(6), 442-447. http://dx.doi.org/10.1089/cyber.2012.0293

Liu, J., Zhou, Y., \& Gu, W. (2009). Reliability and validity of Chinese version of buss-perry aggression questionnaire in adolescents. Chinese Journal of Clinical Psychology, 17, 449-451. http://www.cnki.com.cn/Article/CJFDTotal-ZLCY200904021.htm

Montag, C., Flierl, M., Markett, S., Walter, N., Jurkiewicz, M., \& Reuter, M. (2011). Internet addiction and personality in first-person-shooter video gamers. Journal of Media Psychology: Theories, Methods, and Applications, 23(4), 163-173. http://dx.doi.org/10.1027/1864-1105/a000049

Mehroof, M., \& Griffiths, M. D. (2010). Online Gaming Addiction: The Role of Sensation Seeking, Self-Control, Neuroticism, Aggression, State Anxiety, and Trait Anxiety. Cyberpsychology Behavior and Social Networking, 13(3), 313-316. http://dx.doi.org/10.1089/cyber.2009.0229

Ng, B. D., \& Wiemer-Hastings, P. (2005). Addiction to the Internet and online gaming. Cyberpsychology \& Behavior, 8(2), 110-113. http://dx.doi.org/10.1089/cpb.2005.8.110

Ozdemir, Y., Vazsonyi, A. T., \& Cok, F. (2013). Parenting processes and aggression: The role of self-control among Turkish adolescents. Journal of Adolescence, 36(1), 65-77. http://dx.doi.org/10.1016/j.adolescence.2012.09.004

Peng, W., \& Liu, M. (2010). Online gaming dependency: A preliminary study in China. CyberPsychology, Behavior, and Social Networking, 13(3), 329-333. http://dx.doi.org/10.1089/cyber.2009.0082

Qu, Z., \& Zou, H. (2009). Juvenile delinquency: The role of self-control, family environment and parental $\begin{array}{llll}\text { monitoring. } & \text { Psychological 36ience, } & 32(2), & \text { 360-363. }\end{array}$ http://www.cnki.com.cn/Article/CJFDTotal-XLKX200902027.htm

Quintana, S. M., \& Maxwell, S. E. (1999). Implications of recent developments in structural equation modeling for counseling psychology. The Counseling Psychologist, 27(4), 485-527. http://dx.doi.org/10.1177/0011000099274002

Ronen, T., Abuelaish, I., Rosenbaum, M., Agbaria, Q., \& Hamama, L. (2013). Predictors of aggression among Palestinians in Israel and Gaza: Happiness, need to belong, and self-control. Children and Youth Services Review, 35(1), 47-55. http://dx.doi.org/10.1016/j.childyouth.2012.10.015 
Runions, K. C. (2013). Toward a conceptual model of motive and self-control in cyber-aggression: Rage, revenge, reward, and recreation. Journal of Youth and Adolescence, 42(5), 751-771. http://dx.doi.org/10.1007/s10964-013-9936-2

Shen, C., \& Williams, D. (2011). Unpacking time online: Connecting internet and massively multiplayer online game use with psychosocial well-being. Communication Research, 38(1), 123-149. http://dx.doi.org/10.1177/0093650210377196

Teng, Z., \& Liu, Y. (2013). The role of neuroticism in the relation between self-esteem and aggressive emotion among 1085 Chinese adolescents. Psychology, 4, 729-735. http://dx.doi.org/10.4236/psych.2013.410103

Verona, E., Patrick, C. J., \& Lang, A. R. (2002). A direct assessment of the role of state and trait negative emotion in aggressive behavior. Journal of Abnormal Psychology, 111(2), 249-258. http://dx.doi.org/10.1037/0021-843X.111.2.249

Wang, S., Zhao, R., \& Zhao G. (2006). Current situation investigation, cause analysis and countermeasure research about the internet addiction of the science and engineering college student. Retrieved from May 8 , 2006, http://www.paper.edu.cn/releasepaper/content/200605-37

Wen, Z., Hau, K. T., \& Marsh, H. W. (2004). Structural equation model testing: Cut off criteria for goodness of fit indices and chi-square test. Acta psychologica sinica, 36(2), 186-194. http://118.145.16.229:81/Jweb_xlxb/CN/Y2004/V36/I02/186

Williams, D., \& Skoric, M. (2005). Internet fantasy violence: A test of aggression in an online game. Communication Monographs, 72(2), 217-233. http://dx.doi.org/10.1080/03637750500111781

Winstok, Z. (2009). From self-control capabilities and the need to control others to proactive and reactive aggression among adolescents. Journal of Adolescence, 32(3), 455-466. http://dx.doi.org/10.1016/j.adolescence.2008.08.006

Yan, D. (2013). The negative effects of the violent online games on young people and its circumvention. Chinese Social Sciences Today, 8, 1-3. http://www.qstheory.cn/zl/bkjx/201308/t20130815_260428.htm

Young, K. S. (1998). Internet addiction: The emergence of a new clinical disorder. Cyberpsychology \& Behavior, 1(3), 237-244. http://dx.doi.org/10.1089/cpb.1998.1.237

\section{Notes}

Note 1. Counter-Strike is a first-person shooter video game developed by Valve Corporation. For more information, please see http://en.wikipedia.org/wiki/Counter-Strike.

Note 2. World of Warcraft (WoW) is a massively multiplayer online role-playing game (MMORPG) created by Blizzard Entertainment. For more information, please see http://en.wikipedia.org/wiki/World_of_Warcraft.

Note 3. Crossfire is a board game created by the Milton Bradley Company in 1971. For more information, please see http://en.wikipedia.org/wiki/Crossfire.

\section{Copyrights}

Copyright for this article is retained by the author(s), with first publication rights granted to the journal.

This is an open-access article distributed under the terms and conditions of the Creative Commons Attribution license (http://creativecommons.org/licenses/by/3.0/). 